\section{Health service delivery for type 1 diabetes during the lockdown in Uganda following the coronavirus disease 2019 pandemic}

\author{
Silver Bahendeka, ${ }^{1}$ Thereza Piloya, ${ }^{2}$ \\ Jasper Onono, ${ }^{3}$ Ronald Wesonga, ${ }^{4}$ \\ Gerald Mutungi, ${ }^{5}$ Wenceslaus Sseguya, ${ }^{6}$ \\ Denis Mubangizi ${ }^{6}$ \\ ${ }^{1}$ Department of Internal Medicine, \\ Mother Kevin Post Graduate Medical \\ School, Uganda Martyrs University, \\ Kampala; ${ }^{2}$ Department of Paediatrics, \\ Makerere University College of Health \\ Sciences, Kampala; ${ }^{3}$ IT Department, \\ Diabetes Unit, St. Francis Hospital, \\ Nsambya; ${ }^{4}$ School of Statistics and \\ Planning, Makerere University, \\ Kampala; ${ }^{5}$ NCD Department, Uganda, \\ Ministry of Health; 'Diabetes Centre, St. \\ Francis Hospital, Nsambya, Kampala, \\ Uganda
}

\begin{abstract}
Lockdown measures to reduce the spread of coronavirus disease 2019 (COVID-19), may adversely impact on diabetes supplies and metabolic control, especially in type 1 diabetes in low-resource countries. To address this, we conceptualized a service delivery model that incorporated a digitized tool. The digitized tool (UT1D-HIMAS) maintained electronic health records, monitored clinic supplies, patient clinic visits and admissions, and sent automated SMS messages. Delivery of supplies was by motor vehicles, motorcycles, bicycles or patients/caregivers walking to clinics. Metabolic control was assessed by glycated haemoglobin (HbA1c). Monitoring of clinic supplies including emergency restocking, patient clinic visits and admissions, and sending automated SMS by UT1D-HIMAS were successfully achieved. A fall in clinic visits, reaching a nadir $(67.9 \%)$ in May 2020 was observed. $\mathrm{HbAlc}$ (mean $\pm \mathrm{SD} \mathrm{mmol} / \mathrm{mol}$ ) significantly $(p=0.040)$ worsened from $79.1 \pm 26.8$ to $94.9 \pm 39.2$ and $(\mathrm{p}=0.002)$ from $67.1 \pm 22.7$ to $84.8 \pm 39.4$ in the rural and urban clinic respectively. The digitized health information system exhibited high practicability in tracking stocks, clinic visits and hospitalisation but failed to improve metabolic control.
\end{abstract}

\section{Introduction}

Severe acute respiratory syndrome coronavirus 2 (SARS-CoV-2), the aetiologic agent of coronavirus disease 2019 (COVID-19) is highly contagious. ${ }^{1}$ SARSCoV-2 infection was first reported in Wuhan, Hubei Province, China, in December 2019; and in a few short months the disease had spread globally, prompting the World Health Organization (WHO) to declare it a public health emergency of international concern on January $30^{\text {th }} 2020 .^{2}$ On March 22 nd 2020, the first case of SARS-CoV-2 infection in Uganda was confirmed, prompting the Uganda Government on the March $25^{\text {th }} 2020$ to enforce a lockdown and a nationwide curfew from 19:00 to $05: 30$ hours in order to curb the rapid spread of the disease. ${ }^{3,4}$ This lockdown lasted over two months in most parts of the country. During this period, motor vehicle transportation for the greater public community was largely restricted to those persons charged with providing essential services. The sick in the community and those accessing chronic care services required prior government travel authorization in order to access care. Therefore, there was an urgent need to review the country's health service delivery for type 1 diabetes (T1D) in the light of the restrictive lockdown measures. Significant concerns surrounded the likelihood of interruption of insulin and other essential supplies; inability of the health system to respond to acute metabolic emergencies; and poor outcomes associated with SARS-CoV-2 infection in patients with diabetes. The later was a serious concern, as recent studies in our T1D patients had shown an overall poor metabolic control. ${ }^{5}$

In March 2020, a T1D health care team composed of paediatric and adult endocrinologists, representatives of ministry of health and program managers for T1D met and conceptualized a context-driven health service delivery model to address health service delivery during the COVID-19 pandemic lockdown. The model included a digitized health information system with two main functionalities: i) an application for electronic health care records (EHR) and ii) an administrative system for monitoring supplies and sending automated Short Messaging Services (SMS). Figure 1 shows a schematic diagram of the conceptualized health service delivery model to respond to COVID-19 lockdown. We describe the performance of the health service delivery model in monitoring clinic supplies including emergency restocking, patient clinic visits and admissions, and send-
Correspondence: Silver Bahendeka, Department of Internal Medicine, Mother Kevin Post Graduate Medical School, Uganda Martyrs University, Ground Floor, Doctors Plaza Building, Plot 1470, Nsambya-Gaba Road, P.O Box 32297, Kampala, Uganda.

E-mail: silverbahendeka@gmail.com

Key words: Type 1 diabetes; COVID-19; SARS-CoV-2; lockdown; e-health.

Acknowledgements: We wish to thank the Novo Nordisk Changing Diabetes in Children (CDiC®), Denmark and Life for a Child (LFAC) Sydney for providing support to the T1D program in Uganda. We further would like to appreciate the contributions of Sonia Nabeta Foundation (SNF), which provided funds for boda-boda in distributing the insulin.

Contributions: SKB, TP and RW designed the study; SKB and RW analysed the data; SKB drafted the manuscript and all authors contributed critically to its final form and agreed on the journal for publication.

Conflict of interest: The authors declare no conflict of interest.

Funding: There was no funding for this study Novo Nordisk supports the program of improving care for T1D in Uganda. Novo Nordisk had no role in the design and conduct of the study, collection, management, analysis, and interpretation

Availability of data and materials: All data generated or analyzed during this study are included in this published article.

Ethics approval and consent to participate: The study was approved by the St. Francis Hospital Review and Ethics Committee (UGREC-020) and Uganda National Council of Science and Technology (HS519ES) and was conducted in line with Good Clinical Practice (GCP). All patients participating in this study signed a written informed consent form for participating in this study

Informed consent: Written informed consen was obtained from a legally authorized representative(s) for anonymized patient information to be published in this article

Received for publication: 4 April 2021.

Revision received: 3 November 2021.

Accepted for publication: 11 November 2021

This work is licensed under a Creative Commons Attribution 4.0 License (by-nc 4.0)

${ }^{\circ}$ Copyright: the Author(s), 2021

Licensee PAGEPress, Italy

Healthcare in Low-resource Settings 2021; 9:9799 doi:10.4081/hls.2021.9799 
ing automated SMS; and the impact of lockdown on the metabolic control as assessed by glycaeted haemoglobin (HbA1c).

\section{Subjects}

Participants were all patients with T1D $(n=1473$ in the registry) attending specialized T1D clinics $(n=40)$ in Uganda. The geographical distribution of the clinics is given in the supplemental material (Figure $\mathrm{S} 1)$. There are 40 specialized T1D clinics and all, except one which receives support from Life for a Child (LFAC) programme, are supported by Changing Diabetes in Children $\left(\mathrm{CDiC}^{\circledR}\right)$ Programme. Both the LFAC and $\mathrm{CDiC}^{\circledR}$ have provided free, comprehensive outpatient service to underprivileged children and adolescents with diabetes since 2009. All participants gave informed consent: participants above the age of 18 years consented and parents/guardian consented for children below the age of 18 years (8-18 years of age, in addition to parent/guardian consent, assented). Because of logistics during lockdown, two clinics were conveniently selected for assessment of metabolic control: Virika Hospital, in Fort Portal District, a rural clinic and St. Francis Hospital, in Kampala District, an urban tertiary teaching hospital. The participants in these two clinics were required to have been residents of the respective districts. All patients attend- ing Virika Hospital $(\mathrm{n}=24)$ and a random sample of 42 patients [selected using the electronic health records (EHR) registry as the sampling frame] from St. Francis Hospital, Nsambya (total patients attending this clinic $=180$ ) had HbA1c measured as an assessment of metabolic control.

\section{Materials and Methods}

The management response to the lockdown included the provision of Electronic Health Records (EHR), combined with an administrative digital tool [Uganda Type 1 Diabetes Health Information and Administrative System (UT1D-HIMAS)] that extended geographic access of T1D health service delivery to 40 health units; provided health provider communication to patients; allowed individual patient-level data collection; and had a functionality for clinic stock and inventory. Clinics stocks monitored included insulin, syringes, lancets, strips and glucose meters for patients to carry out Self-Monitoring of Blood Glucose (SMBG), log-books for recording results of SMBG. Selected centres which had the HemoCue ${ }^{\circledR}$ HbA1c 510 analyser monitoring included stocks of cartridges used in the analyser. Health care workers were supplied with $\mathrm{TECNO}^{\circledR}$ android smart phones devices $(165.60 \mathrm{x}$ $73.30 \times 9.10 \mathrm{~cm})$ to connect with UT1D-
HIMAS at the health facility. To enhance the program administrator's monitoring of clinic activity, the following features were incorporated into the UT1D-HIMAS: i) an administrator's notification centre to show notifications on upcoming stock outs for all clinics and patients; ii) a general notification centre (this mirrors the administrator's notification centre, but is related to the logged-in clinic and the clinic patients only). Additionally, it has notifications dispatched by the administrator to healthcare workers; iii) a general notification centre (which mirrors the administrator's notification centre, but is related to the logged-in clinic and the patients patients and, additionally, it has notifications dispatched by the administrator to the healthcare workers; iv) patients' timeline: - stock supplies, laboratory records, clinic records and admissions; v) mobile application (CDiC app) for data entry, with the option of working offline, should internet connectivity be absent.

The following steps were put in place so to achieve a nationwide coordinated response: i) Step 1: all the $40 \mathrm{~T} 1 \mathrm{D}$ clinics were immediately (March 2020) re-stocked with supplies and instructed to give extra insulin supplies and syringes patients. The supplies included insulin, syringes, lancets, strips and glucose meters for patients to carry out self-monitoring of blood glucose (SMBG), log-books for recording results of

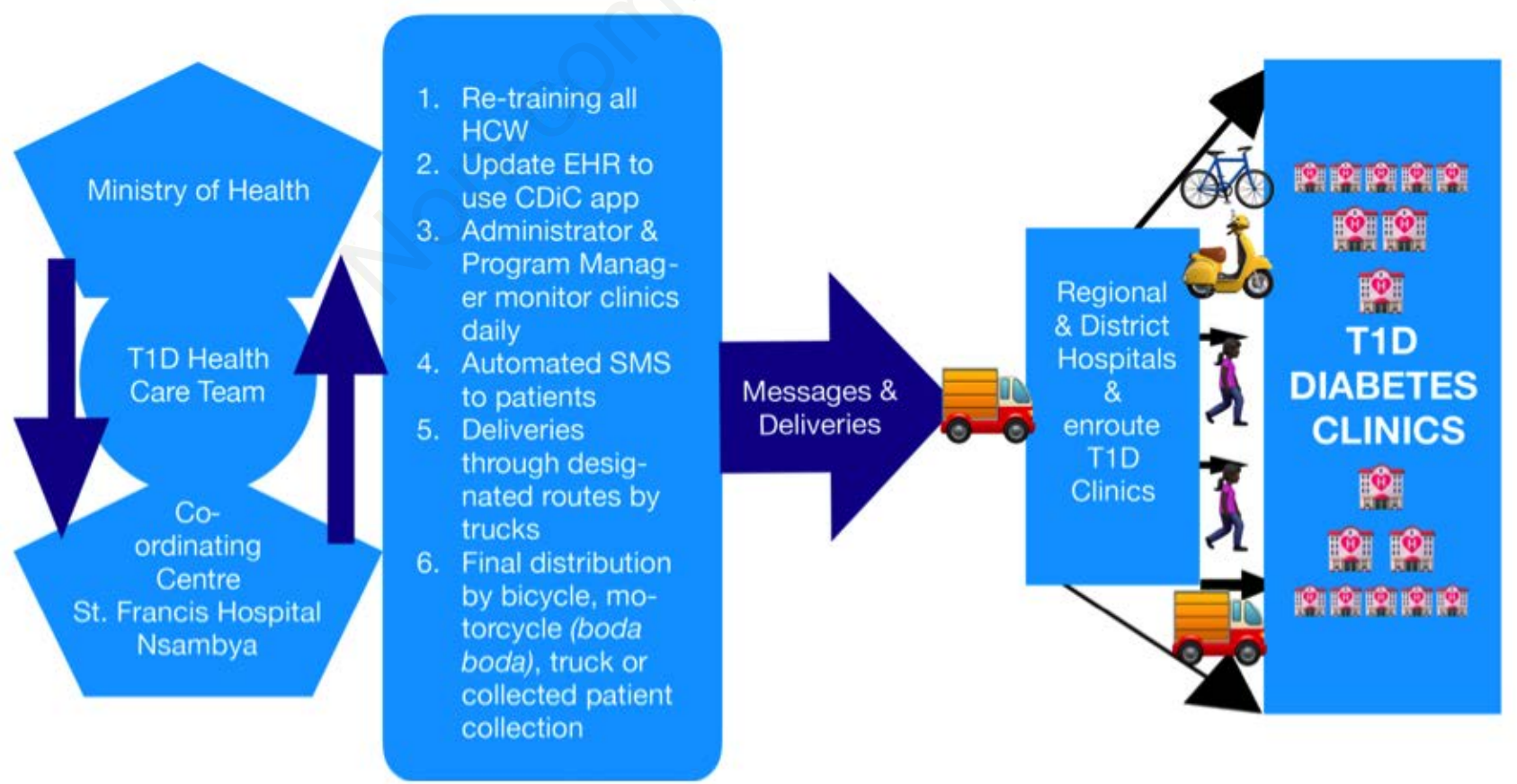

Figure 1. Schematic representation of the conceptualized healthcare delivery response for type 1 diabetes patients during COVID-19 pandemic in Uganda. 
SMBG. Selected centres which had the HemoCue ${ }^{\circledR} \mathrm{HbA1c} 510$ analyser monitoring included stocks of cartridges used in the analyser; ii) Step 2: healthcare workers were sent information on the management of acute respiratory infections with particular emphasis on SARS-CoV-2 infection and reminded of traditional measures to avoid diabetic ketoacidosis (DKA) and further advised on prompt data reporting especially on EHR and diabetes supplies; ii) Step 3: program administrators were to closely follow up clinic stocks and supplies using the administrator's notification centre of UT1D-HIMAS and where required to make a telephone call and discuss with the health workers. The administrators would contact consultant endocrinologists by phone, should there be a clinical problem lower cadres could not solve or the health workers were unable to contact the consultant endocrinologists directly; iv) Step 4: auto- mated SMS in English format were to be sent to all T1D patients regarding clinic services and diabetes management. The system would use telephone numbers recorded at the time of index registration into chronic care.

Glycated haemoglobin (HbA1c) was measured by HemoCue ${ }^{\circledR}$ HbAlc 510 System. Good glycaemic control was regarded as optimal if below $53 \mathrm{mmol} / \mathrm{mol}$. Impact of lockdown on metabolic control was assessed by comparing the most recent $\mathrm{HbA1c}$ before lockdown (performed in February 2020 or March 2020) with that of three months into the lockdown (performed in June 2020) in two sites: one rural - Virika Hospital, Fort-Portal, situated $250 \mathrm{~km}$ from Kampala City and one urban - St. Francis Hospital, Nsambya, a tertiary teaching facility located $3 \mathrm{~km}$ from the centre of Kampala City.

Data was entered into UT1D-HIMAS and later exported into Excel and into STATA Version 15 (1985 - 2017 StataCorp LLC, 4905 Lakeway Drive, College Station, Texas 77845 USA) for analysis. A p value $<0.05$ was considered statistically significant.

The study was approved by the St. Francis Hospital Review and Ethics Committee (UG-REC-020) and the Uganda National Council of Science and Technology (HS519ES) and was conducted in line with Good Clinical Practice (GCP).

\section{Results}

\section{The Uganda Type 1Diabetes Health Information Management Administration System (UT1D-HIMAS)}

The UT1D-HIMAS digital tool was

Table 1. Clinic status 14 weeks before and 14 weeks after SARS-CoV-2 infection was confirmed in Uganda.

\section{Description} Period 14 Weeks before lockdown Period 14 Weeks into lockdown

Number of T1D clinics

Total number T1D registered at end of period in EHR

$40 \quad 40$

Patients enrolled into chronic care during period

1408

1483

T1D Attending clinic but not previously captured in EHR

41

Known T1D enrolled into specialized clinics but previously attending the elsewhere

T1D presenting with hyperglycaemia; $\mathrm{BG}>15 \mathrm{mmol} / /$ (New-onset diabetes)

$7(7)$

59

Deaths

0

$20(6)$

Note: The Uganda Government enforced the lockdown restrictive measures on 25 March 2020 and began to relax them for majority of the population at the end of June 2020 . Abbreviations: BG, Blood Glucose; EHR, Electronic Healthcare Records; T1D, Type 1 Diabetes.

Table 2. Characteristics of patients presenting with hyperglycaemia (blood glucose $>15 \mathrm{mmol} / \mathrm{l})$ before and after the lockdown.

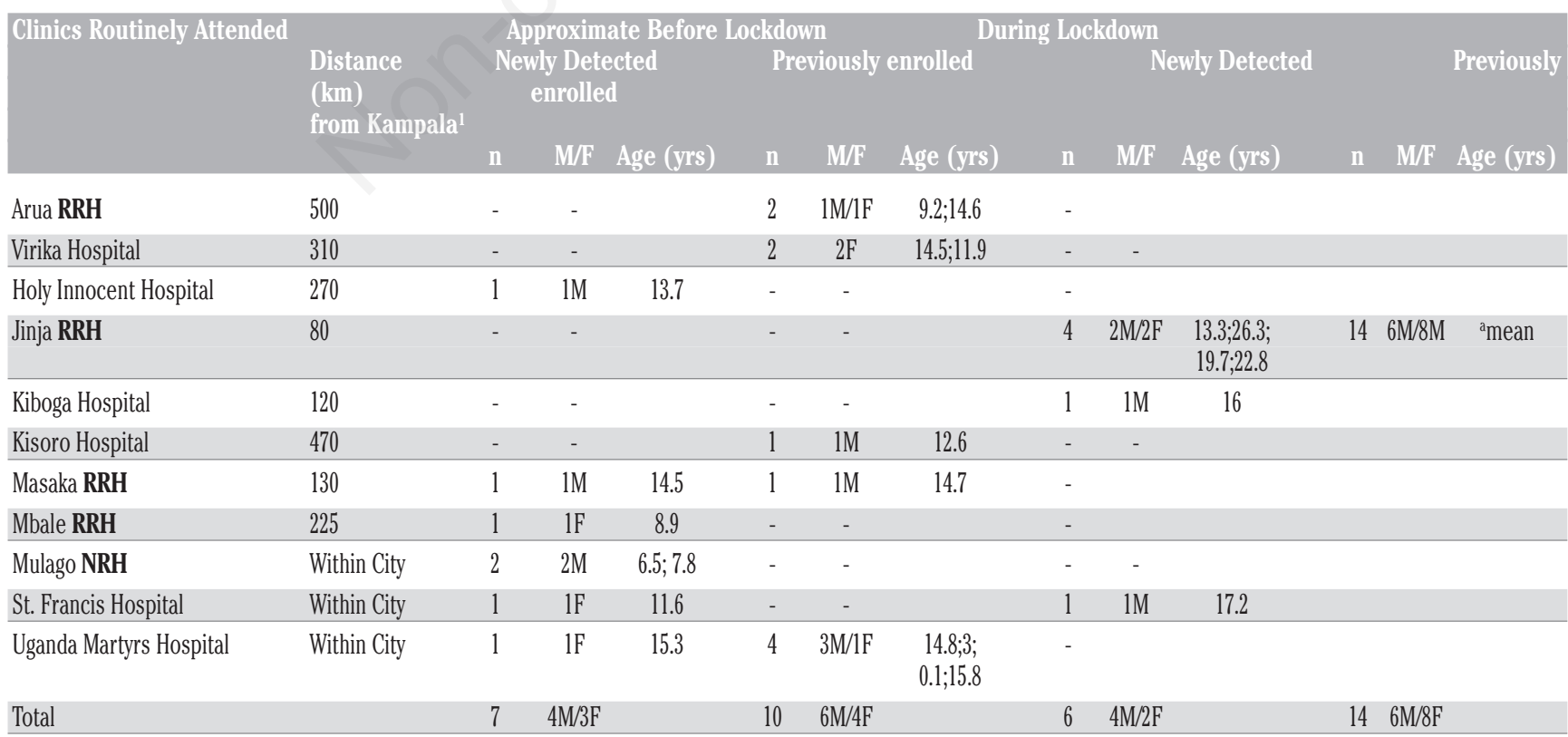

Note: The number of patients who enrolled into chronic care with the type 1 diabetes clinics and had been under care in other health facilities was highest in Jinja Hospital and are here given as Mean \pm SD. Abbreviations: F, Female M, Male; NRH, National Referral Hospital. RRH, Regional Referral Hospital; SD, Standard deviation yrs, years; 1 Kampala is the Capital City of Uganda. 2 Mean \pm SD $14.2 \pm 5.6$ years; range $2.8-$ 26.3 years. 
operationalized in March 2020 and enabled electronic collection, storage, management and sharing of patient's electronic health records for purposes of patient care, research and quality management. Figure 2 shows a computer screen caption of a typical administrator dashboard in UT1DHIMAS clinic activity in June 2020.

Thirty-one $(77.5 \%)$ clinics responded to all SMS and telephone calls from the administrator during the lockdown period. The system automatically sent SMS notification reminders to all T1D patients with active telephone numbers [1310 (88.9\%)] for any upcoming clinic planned visits and reminders if the patient did not fulfil the appointment. Reminders on missed appointments averaged $60 \%$ per month during the lockdown period. The system did not have the functionality to note received SMS.

\section{Type 1 diabetes clinics}

During the lockdown period, a further 75 patients were captured into EHR; 10 of who were already attending the clinics but data not entered into EHR; 6 had newly detected diabetes and the rest 59 had been attending other health facilities. A total of 20 patients presented with hyperglycaemia (glucose above $15 \mathrm{mmol} / \mathrm{L}$ ); 19 were managed on outpatient basis while one patient with malaria required admission. There was no reported case of SARS-CoV-2 infection in T1D; and no deaths. Table 1 shows the status of the clinics 14 weeks before and 14 weeks after SARS-CoV-2 infection was confirmed in Uganda. Table 2 shows the characteristics of patients who presented with hyperglycaemia during the period before and period during the lockdown.

Clinic attendance fell during the lockdown period, and began to pick up in June 2020. The average clinic attendance in January and February 2020 (before lockdown) was 1,304, and fell by $9.6 \%$ in March (total attendance 1,179); by $17.8 \%$ in April (total attendance 1,072); by $67.9 \%$ in May (total attendance 419 ) and by $24.4 \%$ in June (total attendance 991). Figure 3 shows a histogram of clinic visits before and during the period of lockdown in Uganda. Emergency Diabetes Supplies

In May 2020, all the 40 clinics centres were restocked with diabetes supplies. Patients or their contact neighbours or peers were contacted by SMS or phone calls and supplies sent on motorcycles or bicycles in line with the conceptualized intervention. There was no reported case of a complete day's out of stock of insulin and no clinic reported insulin stock outs. However, we noted that prior to the lockdown, there was a shortage of strips for Self-Monitoring of Blood Glucose (SMBG) in $36(90 \%)$ clinics. Blood glucose monitoring strips arrived in the country in May 2020 and restocking of the clinics was done with other diabetes supplies.

\section{Glycaemic control}

Table 3 summarises $\mathrm{HbA} 1 \mathrm{c}$ before and during the lockdown in two selected clinics: Virika and St. Francis Hospitals. Prior to the lockdown, the mean HbA1c in St. Francis

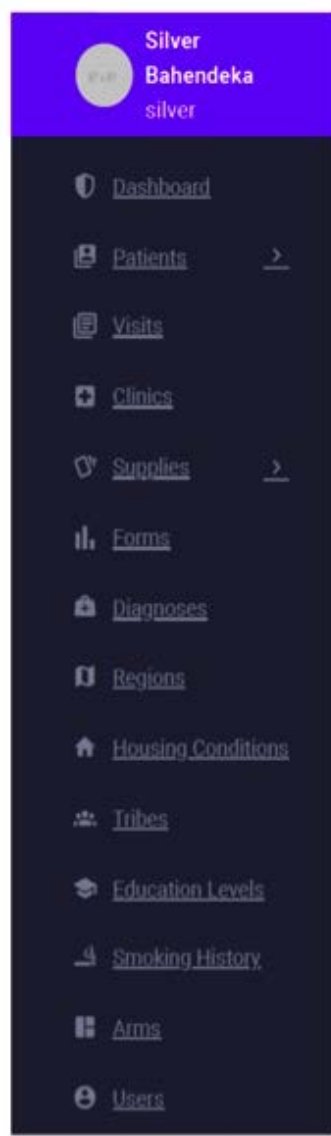

Dashboard
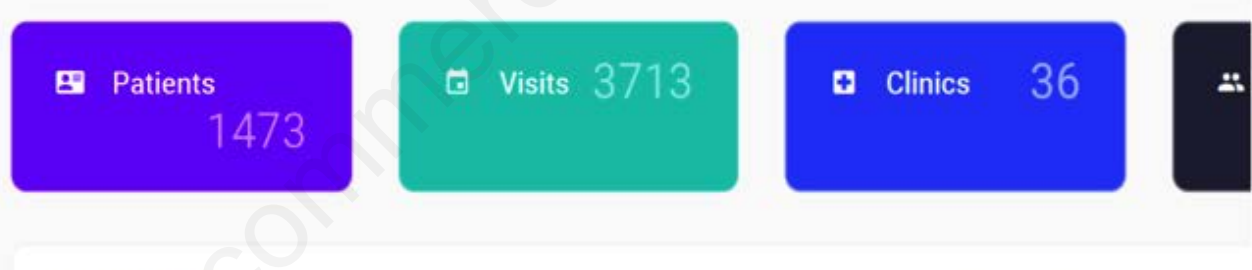

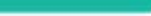

Clinic Visits (Last 30 Days)

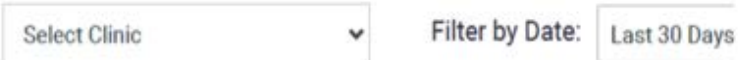

15
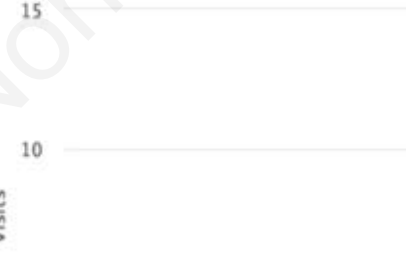

5

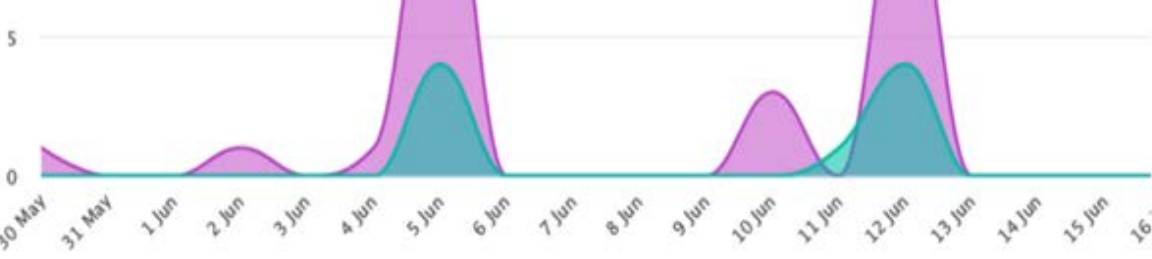

Repeat Visits

Index Visits

Figure 2. A caption of a typical administrator's dashboard screen view showing clinic visits in the month of June 2020. Purple curves represent repeat visits and green curves represent index clinic visits. Four clinics were offline. 
Hospital was $67.2 \mathrm{mmol} / \mathrm{mol}$ significantly ( $p=0.05$ ) lower than the mean HbA1c of $79.2 \mathrm{mmol} / \mathrm{mol}$ in Virika Hospital. There was worsening of HbAlc in both clinics with the lockdown; mean HbA1c three months into the lockdown (June 2020) was significantly $(p=0.002)$ higher at 84.7 $\mathrm{mmol} / \mathrm{mol}$ in St. Francis Hospital and similarly significantly $(p=0.04)$ higher at 94.5 $\mathrm{mmol} / \mathrm{mol}$ in Virika Hospital. The previous gradient observed between Virika Hospital (a rural clinic) and St. Francis Hospital (an urban teaching facility) narrowed; $31.0 \%$ patients had HbA1c below $53 \mathrm{mmol} / \mathrm{mol}$ in St. Francis Hospital versus $16.7 \%$ in Virika Hospital before the lockdown, dropping down to $23.8 \%$ and $12.5 \%$ during lock down in St. Francis Hospital and Virika Hospital respectively.

\section{Discussion}

The T1D health care team in Uganda conceptualized a national response that included EHR combined with an information and administrative digitized tool and guidelines for healthcare workers to address adverse effects of lockdown restrictive measures on diabetes supplies and metabolic control among T1D patients. The conceptualized response to the lockdown successfully avoided severe shortages of diabetes supplies but unfortunately failed to improve glycaemic control.

The success achieved in avoiding insulin and other essential diabetes supplies stock outs is attributed to the rapid inflow of information enabled by the digital health services that comprised of appropriately and promptly entering clinic and patient data by health care workers into the application of the digital tool, the program administrators utilising a digital tool to monitor the stocks and supplies backed by the use of phone calls and SMS. For this exercise to be completed, there was need to utilise all locally available means of delivering and collecting supplies: motor vehicles, motorcycles (boda boda), and in some cases, patients and/or their care givers walking to and from the T1D specialized clinics to collect the diabetes supplies. While the later may have imposed some hardships on the patients and/or their care givers, it should be seen as an important component of developing telehealth in low resource countries, as it entailed a culture change among providers and institutions, provided early contextually driven engagement of institutional stakeholders in the development of a formal telehealth onboarding process for patients and/or care givers, providers and staff.

Clinical operations using the digital tool were limited to EHR and SMS for patient reminders about clinic visits and other general clinic information. This was because the technological requirements of more elaborate clinical operations that would promote patient-driven, patient-centred diabetes care with individualized content and timing was not available and would not be

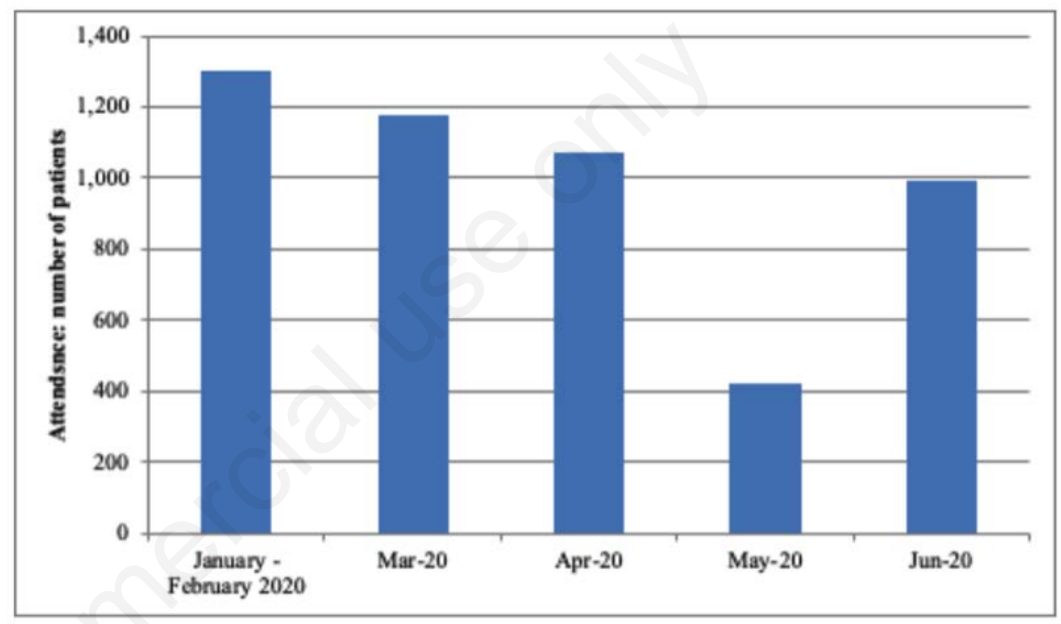

Figure 3. A histogram showing clinic visits before and during the period of lockdown in Uganda. The bar of January - February 2020 represents the average attendance just prior to the lockdown restrictive measures enforced in March 2020. The rest of the bars represent actual visits as recorded at the clinic during the months of March to June.

Table 3. A summary of glycated haemoglobin (HbA1c) for patients attending Virika Hospital, Fort Portal and St. Francis Hospital, Nsambya, Kampala before and during the lockdown.

\begin{tabular}{|c|c|c|c|}
\hline Characteristic & $\begin{array}{l}\text { Virika Hospital, } \\
\text { Fort Portal (rural) }\end{array}$ & $\begin{array}{l}\text { St. Francis Hospital, } \\
\text { Kampala (urban) }\end{array}$ & p value \\
\hline Distance of Clinic from Kampala (Km) & 250 & 3 & - \\
\hline Patients registered in clinic $(\mathrm{M} / \mathrm{F})$ & $66(37 / 29)$ & $257(121 / 136)$ & - \\
\hline Patients enrolled for HbAlc (M/F) & $24(6 / 18)$ & $42(24 / 18)$ & - \\
\hline Participants mean age in years (range) & $17(4-23)$ & $22(9-32)$ & - \\
\hline $\begin{array}{l}\text { Aggregated HbAlc (mmol/mol) Before Lockdown (December- February 2020) } \\
\% \text { HbAlc }<53 \mathrm{mmol} / \mathrm{mol} \\
\% \mathrm{HbAlc} 53-64 \mathrm{mmol} / \mathrm{mol} \\
\% \mathrm{HbAlc} 65-75 \mathrm{mmol} / \mathrm{mol} \\
\% \mathrm{HbAlc}>75 \mathrm{mmol} / \mathrm{mol}\end{array}$ & $\begin{array}{l}79.1 \pm 26.8 \\
16.7 \\
12.5 \\
25.0 \\
45.8\end{array}$ & $\begin{array}{l}67.1 \pm 22.7 \\
30.9 \\
21.4 \\
11.9 \\
35.7\end{array}$ & $\begin{array}{l}0.05 \\
- \\
- \\
- \\
-\end{array}$ \\
\hline $\begin{array}{l}\text { Aggregated HbAlc }(\mathrm{mmol} / \mathrm{mol}) \text { during Lockdown (March- June } 2020) \\
\% \mathrm{HbAlc}<53 \mathrm{mmol} / \mathrm{mol} \\
\% \mathrm{HbAlc} 53-64 \mathrm{mmol} / \mathrm{mol} \\
\% \mathrm{HbAlc} 65-75 \mathrm{mmol} / \mathrm{mol} \\
\% \mathrm{HbAlc}>75 \mathrm{mmol} / \mathrm{mol}\end{array}$ & $\begin{array}{l}94.9 \pm 39.2 \\
12.5 \\
8.3 \\
16.7 \\
62.5\end{array}$ & $\begin{array}{c}84.8 \pm 39.4 \\
23.8 \\
16.7 \\
2.4 \\
57.1\end{array}$ & $\begin{array}{c}0.31 \\
- \\
- \\
- \\
-\end{array}$ \\
\hline HbAlc change before and three months after lockdown: $p$ value & 0.040 & 0.002 & \\
\hline
\end{tabular}


supported by the existing infrastructure. The proportion of Ugandan households with at least one telephone is $10.8 \%(10.6 \%$ rural; $11.1 \%$ urban) while only $5.9 \%$ of all households have access to a computer at home. Only $15.8 \%$ of the individuals who own a mobile phone, owns a smart phone; however, $98.7 \%$ of the households agree to share a phone. SMS was therefore a good option for keeping in touch with patients and a positive step towards building a more elaborate diabetes telehealth. ${ }^{7,8}$

In our Ugandan T1D patients, the conceptualized response to the lockdown failed to improve the metabolic control. We suggest this could have been due to multiple factors. First, Diabetes Self-Management Education (DSME), a major factor underlying poor metabolic control among T1D patients in Uganda ${ }^{5,9,10}$ could not be addressed by the tool. Secondly, the lockdown prevented adequate clinic visits and consequently patients had very little support from healthcare workers, whether or not it was a rural or an urban setting. Thirdly, other factors that we did not address, like excessive consumption of juices and other sugars during lockdown, reduction in exercise activity, change in dietary patterns, reduced monitoring for fear of running out of supplies may have been contributing factors to the observed metabolic dysregulation. ${ }^{11-13}$

Recent studies from the high-income countries suggest that patients of all ages with T1D did not experience a deterioration in their glucose control through the lockdown. ${ }^{14}$ The use of telemedicine was reported as the leading factor in the improvement of metabolic control during the lockdown of the COVID-19 pandemic. ${ }^{14}$ This option was not possible as the infrastructure in Uganda cannot support telemedicine.

As of February 18, 2021, Uganda was still in a very fortunate position of having moderate spread of SARS-CoV-2 infection. ${ }^{15}$ No case of SARS-CoV-2 infection had been reported among patients with T1D.

\section{Study limitations}

SMS were given in the English format. Some T1D or their care givers may not have understood the SMS as some may not have been fluent in the English language. Uganda has over 45 officially recognised local languages. ${ }^{16}$

At enrolment into chronic care patients are required to register a mobile phone that may be used to reach him/her. When the T1D patient or his family/caregiver did not own a phone, they gave the neighbour's or local leader's phone contact, which is what was used for SMS. It is envisaged that in such cases some SMS were not delivered or delivered late.

Few patients or their neighbours had smart phones, hence the SMS had to be very basic and therefore no significant DSME could be incorporated.

Calls and SMS to the healthcare workers were not tollfree, which may have acted as a barrier to patients calling for assistance during lockdown.

Monitoring was emphasised, but strips were not available until May 2020.

Because of logistical problems, only two clinics were conveniently chosen for the assessment of metabolic control during the lockdown. Therefore, caution needs to be exercised in conclusions drawn from these clinics, rural and urban, as they may not be generalised to all the clinics.

The strength of this study is the inclusion of all specialized T1D clinics from Uganda for the monitoring of diabetes supplies and stock-outs (only two clinics were included to evaluate metabolic control), a significant achievement in overcoming geographic barriers to accessing care.

\section{Conclusions}

The conceptualized response to the lockdown that utilised a digitized health information system based on a context-driven health service delivery model exhibited a high practicability and efficiency in tracking stocks and delivery of diabetes supplies, but failed to mitigate worsening of glycaemic control.

\section{References}

1. Yesudhas D, Srivastava A, Gromiha MM. COVID-19 outbreak: history, mechanism, transmission, structural studies and therapeutics. Infection 2021;49:199-213.

2. World Health Organization. (2020). WHO Director-General's opening remarks at the media briefing on COVID-19 - 11 March 2020. Accessed on 15 August 2020. Avalable from: https://www.who.int/dg/speeches/detail /who-director-general-s-openingremarks-at-the-media-briefing-oncovid-19---11-march-2020

3. Federica M, Pattnaik A, Jordanwood T, et al. (2020). Case study: The initial COVID-19 response in Uganda. Washington, DC: ThinkWell and Ministry of Health Uganda. Accessed on 23 October 2021. Available from: https://thinkwe1l.global/wpcontent/uploads/2020/09/Uganda-
COVID-19-Case-Study- 18-Sept20201.pdf

4. Migisha R, Kwesiga B, Mirembe BB, et al. Early cases of SARS-CoV-2 infection in Uganda: epidemiology and lessons learned from risk-based testing approaches - March-April 2020. Global Health 2020;16:114.

5. Bahendeka S, Mutungi G, Tugumisirize F, et al. Healthcare delivery for paediatric and adolescent diabetes in low resource settings: Type 1 diabetes clinics in Uganda. Global Public Health 2019.

doi:

10.1080/17441692.2019.1611897

6. Collaboration on International ICT Policy for East and Southern Africa (CIPESA). (2018) National Information Technology Survey 2017/18 Report. Accessed 03 March 2020. available from: https://www.nita.go.ug/sites/ default/files/publications/National\%20I T\%20Survey\%20April\%2010th.pdf

7. Hartmann-Boyce J, Morris E, Goyder $\mathrm{C}$, et al. Managing diabetes during the COVID-19 pandemic2020. Accessed on 06 February 2021. Available from: https://www.cebm.net/covid-19/managing-diabetes-during-the-covid-19-pandemic/

8. Kompala T, Neinstein AB. Telehealth in type 1 diabetes. Curr Opin Endocrinol Diabetes Obes 2021;28:21-9.

9. Kyokunzire C, Matovu N. Factors associated with adherence to diabetes care recommendations among children and adolescents with type 1 diabetes: a facility-based study in two urban diabetes clinics in Uganda. Diabet Metabol Syndr Obes Targets Ther 2018;11:93104.

10. Mbanya JC, Naidoo P, Kolawole BA, et al. Management of adult patients with type 1 diabetes mellitus in Africa: A post-hoc cohort analysis of 12 African countries participating in the International Diabetes Management Practices Study (Wave 7). Medicine (Baltimore) 2020;99:e20553.

11. Tenywa G. COVID-19: Foods you must eat to boost your immunity. New Vision, 2020. Accessed on 31st March 2020. Available from: https://www.newvision.co.ug/news/151 7308/covid-19-foods-eat-boost-immunity

12. Kasozi KI, MacLeod E, Ssempijja F, et al. Misconceptions on COVID-19 Risk Among Ugandan Men: Results From a Rapid Exploratory Survey, April 2020. Front Public Health 2020;8:416.

13. Usman IM, Ssempijja F, Ssebuufu R, et al. Community Drivers Affecting Adherence to WHO Guidelines Against 
COVID-19 Amongst Rural Ugandan Market Vendors. Front Public Health 2020;8:340.

14. Trevisani I, Bruzzi P, Madeo SF, et al. COVID-19 and Type 1 Diabetes: Concerns and Challenges. Acta Biomed 2020;91:e2020033.
15. Ministry of Health Uganda Government. Uganda Government, Ministry of Health, Coronavirus (Pandemic) COVID-19, 2020: Accessed on 28 June 2020. Available from: https://www.health.go.ug/covid/

16. Igloos Consultancy: Francis. (2019).
How many languages Uganda has? Accessed on 10 October 2020. Available from: https://igloosconsultancyservices.com/how-many-languagesuganda-has/ 